\title{
Etiologic role of Borrelia burgdorferi in morphea: A case report
}

\author{
FLORICA ȘANDRU ${ }^{1,2}$, ADELINA POPA $^{2}$, AIDA PETCA ${ }^{1,3}$, \\ RALUCA-GABRIELA MIULESCU ${ }^{2}$, MARIA MAGDALENA CONSTANTIN ${ }^{1,4}$, \\ RĂZVAN-COSMIN PETCA ${ }^{1,5}$, TRAIAN CONSTANTIN ${ }^{5}$ and MIHAI CRISTIAN DUMITRAȘCU ${ }^{1,6}$

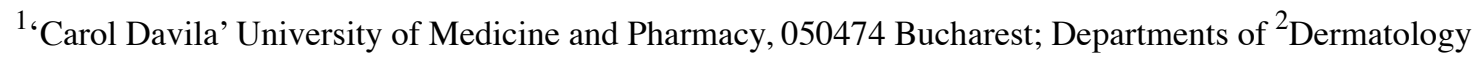 \\ and ${ }^{3}$ Obstetrics and Gynecology, 'Elias' Emergency University Hospital, 011461 Bucharest; \\ ${ }^{4}$ Department of Dermatology II, Colentina Clinical Hospital, 020125 Bucharest; ${ }^{5}$ Department of Urology, \\ 'Prof. Dr. Theodor Burghele' Clinical Hospital, 061344 Bucharest; ${ }^{6}$ Department of Obstetrics and Gynecology, \\ Bucharest Emergency University Hospital, 050098 Bucharest, Romania
}

Received January 10, 2020; Accepted February 12, 2020

DOI: $10.3892 / \mathrm{etm} .2020 .8815$

\begin{abstract}
Morphea is an inflammatory skin disease with self-limited evolution, presenting as localized sclerosis of the skin and/or underlying tissues. The incidence is not exactly known; the disease occurs more frequently in women, and there is no sex prevalence. Pathogenesis of morphea remains still controversial. Several theories exist and the Borrelia burgdorferi infection is not yet elucidated. The aim of this report is to present the main mechanisms involved in the etiophatogenesis of morphea and also the thepapeutic options. A case of a 60 -year-old woman is presented, who was referred to the clinic for an erythematous-violaceus, asymptomatic eruption, located on the trunk and legs, for appoximately 2 months. The patient's medical history revealed an infection with Borrelia 1 year previously. After diagnosis of morphea was established, and with systemic therapy (corticosteroids and methotrexate), the evolution was favorable.
\end{abstract}

\section{Introduction}

Mophea, also known as localized scleroderma (LSc) or circumscribed scleroderma, is an inflammatory cutaneous condition, characterized by localized sclerosis of the skin (1). Morphea presents as single or multiple inflammatory or sclerotic plaques, which are usually active for 3-6 years (2). This skin condition presents in several clinical forms: plaque

Correspondence to: Dr Raluca-Gabriela Miulescu, Department of Dermatology, 'Elias’ Emergency University Hospital, 17 Marasti Bvd., 011461 Bucharest, Romania

E-mail: miulescuraluca@yahoo.com

Abbreviations: LSc, localized scleroderma; ssDNA, anti-singlestranded DNA; dsDNA, anti-double-stranded DNA

Key words: morphea, Borrelia burgdorferi, corticosteroids, methotrexate (circumscribed), generalized, linear (en coup de sabre) and deep morphea. Also, we can classify morphea in: superficial (primarily dermal) or deep (involving the deep dermis plus the subcutis, fascia, and/or bone) (3). In most cases, the diagnosis of morphea is clinical. Sometimes, the histopathological examination may be useful (4). The treatment depends on the stage and extension of morphea (5).

\section{Case report}

A case of a 60 year-old woman is presented, who was referred to the Dermatology Clinic for an evaluation of erythematous-violaceus, asymptomatic eruption, located on the trunk and legs, in evolution for 2 months. Her medical history revealed an infection with Borrelia burgdorferi (1 year previously) (Fig. 1), and dyslipidemia. The patient was informed of the study and written informed consent was obtained from the patient.

Physical examination showed grade II obesity. Clinical examination revelead numerous erythematous-purple plaques, indurated, relatively well delimited, with irregular edges, with central atrophy, diameter 2-7 cm, disseminated at the level of the trunk and lower limbs (Fig. 2).

Routine laboratory tests revealed inflammatory syndrome and dyslipidemia. Radiological examination and abdominal-pelvic ultrasound were within normal limits. Because a form of morphea was suspected, several autoantibodies were evaluated and antinuclear antibody serum levels were elevated; anti-single-stranded DNA (ssDNA), anti-double-stranded DNA (dsDNA), antihistone, anti-topoisomerase II $\alpha$ and antiphospholipid antibodies were negative. The medical history of our patient revealed infection with Borrelia, which is known as an etiologic factor of morphea.

Generalized morphea was suspected, so a skin biopsy from a lesion was prelevated, and the histopathological examination revealed moderate orthokeratosis and minimal epidermal basal pigmentation; at the dermal level, areas of fibrosis were identified, which focally compressed the attached structures (ducts and sweat glands); minimal inflammatory lymphocyte inflitrate, predominantly perinaexial or perivascular; papillary 


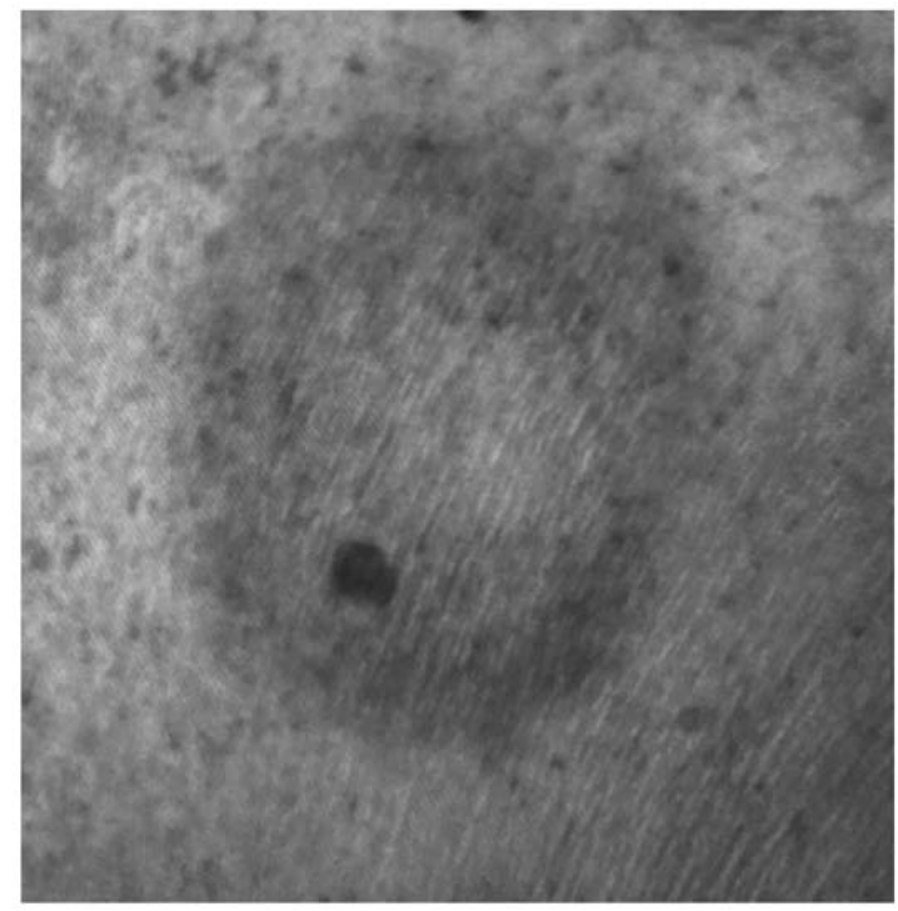

Figure 1. Infection with Borrelia (erythema migrans).

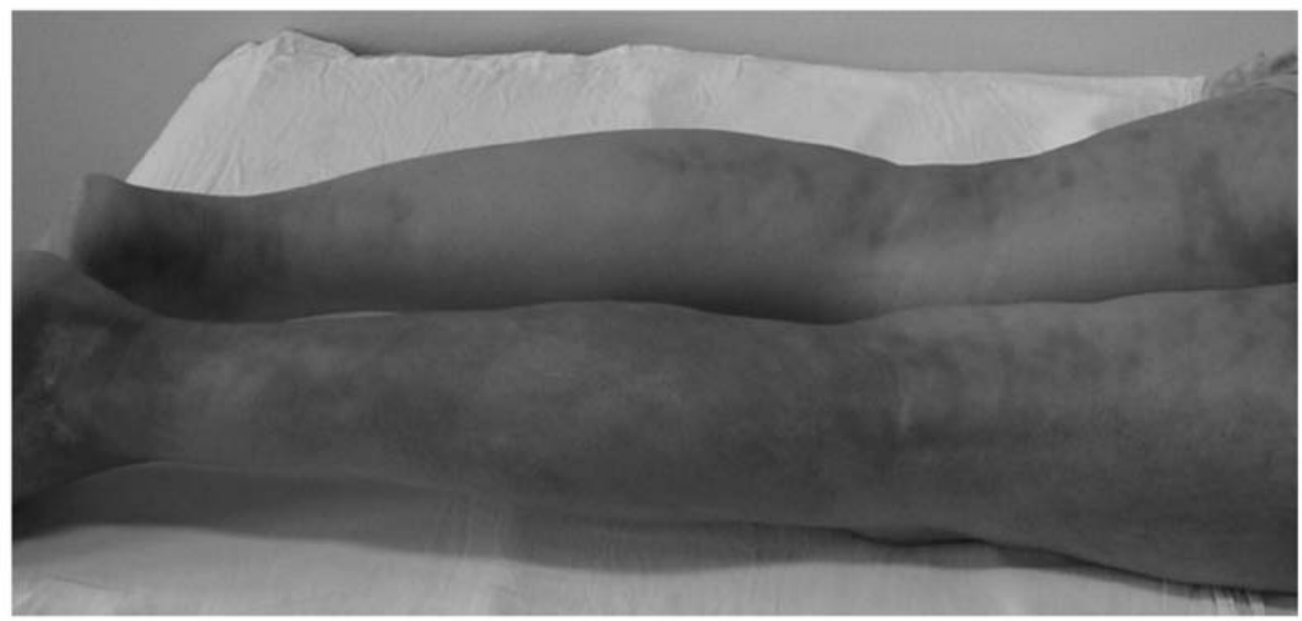

Figure 2. Multiple indurated plaques, on the lower limbs.

dermis with homogenized appearance and turgid capillaries. The histopathological findings supported the clinical diagnosis of morphea. Corroborating the clinical, paraclinical data and histopathological examination, the final diagnosis of generalized morphea was establised.

The patient was hospitalized, and systemic treatment initiated with corticosteroids (prednisolone $1 \mathrm{mg} / \mathrm{kg}$ per day, slowly decreasing), associated with gastric protection and methotrexate $15 \mathrm{mg} /$ week, administered subcutaneously. This treatment was chosen because there were multiple, indurated, and disseminated lesions. As local treatment, the patient applied tacrolimus $0.1 \%$ ointment. During hospitalization, the evolution was favorable, with improvement of lesions. Upon discharge, continuation of prednisolone in decreasing doses, with gastric protection, continuation of the same dose of methotrexate, and local treatment were recommended.
Four weeks after discharge, our patient presented to evaluation, the evolution was favorable, with improvement of injuries and induration. Moreover, there was no more inflammation of the lesions. The recommendations were: continuing the cortizonic treatment, with decreasing doses as in the initial scheme, under gastric protection; keeping the same dose of methotrexate and local treatment.

\section{Discussion}

The etiopathogenesis of morphea is not well understood. Drugs, local trauma, environmental toxins or infections may be involved in the pathogenesis. There are two processes that trigger the disease: abnormal fibroblast function and immune dysfunction resulting in autoimmunity (6). The possible mechanism involved in pathogenesis of morphea, also in 
our patient, may be the infection with Borrelia burgdorferi. According to some authors, increased levels of antibodies against this organism, was higher in patients with morphea compared with controls. They also identified Borrelia DNA in skin biopsies of patients with morphea, using polymerase chain reaction (7-9). This theory is quite controversial, because other studies did not show any association between morphea and Borrelia (10). A review concluded that Borrelia infection may not be involved in triggering morphea, or that only some species of Borrelia that live in few countries in Europe and Asia may lead to developing this skin condition (11). However, this subject remains to be further studied: some authors suggested that Borrelia may be responsable for morphea, as they reported a case of a patient with morphea and this infection (12).

In some cases of morphea, the diagnosis of certainty is established by histopathological examination. A skin biopsy can be taken from the inflammatory margin or from the central sclerosis. It is always important to take the biopsy with subcutaneous fat, because the changes are seen at the border between the dermis and subcutaneous fat. At the inflammatory border, interstitial and perivascular inflammatory cell infiltrate is found (lymphocytes, plasma cells, eosinophils, mast cells, macrophages). In contrast, the atrophic phase reveals loss of inflammatory cell infiltrate, less sclerosis and absence of appendageal structures. Some authors suggested that patients with a histopathological pattern of sclerosis were associated with pain more often than others (4).

The treatment of morphea varies depending on the severity of the disease. Circumscribed lesions respond well to low-concentration dermatocorticoids, intralesional corticosteroids, topical tacrolimus or topical calcipotrione (13). In moderate-to-severe disease (for example, generalized morphea), first line therapy is represented by methotrexate, with or without corticosteroids (14). In non-responsive patients, other systemic treatments may be beneficial: mycofenolate mofetil, colchicine or cyclosporine (15). Infliximab, an anti-TNF- $\alpha$ agent, is a human-murine chimeric drug, composed by a constant human region and a variable mouse region $(16,17)$. Althought a report of a clinical case responding to this biologic agent exists, there are not enought data to support the efficacy of this drug (18).

Patients need to be educated on their comorbidities. In case of our patient, who had associated dyslipidemia and obesity, it was important to inform her of the risks of visceral fat level (especially when treatment with methotrexate was administered) (19).

Morphea is a chronic disorder, with periods of exacerbations and remissions. It is important to follow up the patients with morphea: every 2-4 months during the first year. After the disease is under control, one visit each 6 months is sufficient. Followed by one control per year, for clinical evaluation should be enough. Whereas, if the disease is getting worse, the patient should immediately present to examination (20).

In conclusion, the etiophatogenesis of morphea is not yet elucidated. Several mechanisms may be involved, and the infection with Borrelia burgdorferi may be one of them. This is why the medical history of the patient is very important. The treatment of morphea varies depending on the severity of the disease and follow-up of these patients is required.

\section{Acknowledgements}

Not applicable.

\section{Funding}

No funding was received.

\section{Availability of data and materials}

The datasets used and analyzed during the current study are available from the corresponding author on reasonable request.

\section{Authors' contributions}

FS was involved in the writing of the manuscript and was responsible for the patient follow up based on clinical and paraclinical examinations. APo was involved in the conception of the case study. APe analyzed the data from literature regarding the etiologic role of Borrelia burgdorferi in morphea and was involved in the writing of the manuscript. RGM was responsible for the figures and the final aspect of the manuscript. MMC analyzed the histological characteristics of the lesions and was responsible for the writing of the relevant section of the manuscript. RCP analyzed the main mechanisms involved in the etiophatogenesis of morphea and was responsible for the writing of the relevant section of the manuscript. TC examined the patient and wrote the section regarding the clinical examination of the lesions. MCD was involved in the conception and writing of the manuscript. All authors critically revised the manuscript and approved the final version to be published.

\section{Ethics approval and consent to participate}

Not applicable.

\section{Patient consent for publication}

Written informed consent was obtained from the patient.

\section{Competing interests}

The authors declare that they have no competing interests.

\section{References}

1. Jablonska S: The concept of scleroderma and its classification. In: Scleroderma and Pseudoscleroderma. Jablonska S (ed). Polish Medical Publishers, Warsaw, pp3-10, 1975.

2. Provost TT, Greenberg AS and Falanga V: Localized cutaneous sclerosis. In: Cutaneous Manifestations of Rheumatic Diseases. 1st edition. Sontheimer RD and Provost TT (eds). Williams \& Wilkins, Baltimore, MD, p125, 1996.

3. Laxer RM and Zulian F: Localized scleroderma. Curr Opin Rheumatol 18: 606-613, 2006.

4. Jacobe H: Pathogenesis, clinical manifestations, and diagnosis of morphea (localized scleroderma) in adults - UpToDate. https://www. uptodate.com/contents/pathogenesis-clinical-manifestations-and-d iagnosis-of-morphea-localized-scleroderma-in-adults. Accessed May $31,2019$. 
5. Jacobe H: Treatment of morphea (localized scleroderma) in adults - UpToDate.https://www.uptodate.com/contents/treatmentof-morphea-localized-scleroderma-in-adults. Accessed April 16 2018.

6. Zulian F: Localized scleroderma in childhood - UpToDate. https://www.uptodate.com/contents/localized-scleroderma-inchildhood. Accessed April 3, 2019.

7. Aberer E, Kollegger H, Kristoferitsch W and Stanek G: Neuroborreliosis in morphea and lichen sclerosus et atrophicus. J Am Acad Dermatol 19: 820-825, 1988.

8. Aberer E, Stanek G, Ertl M and Neumann R: Evidence for spirochetal origin of circumscribed scleroderma (morphea). Acta Derm Venereol 67: 225-231, 1987.

9. Schempp C, Bocklage H, Lange R, Kölmel HW, Orfanos CE and Gollnick H: Further evidence for Borrelia burgdorferi infection in morphea and lichen sclerosus et atrophicus confirmed by DNA amplification. J Invest Dermatol 100: 717-720, 1993.

10. Wienecke R, Schlüpen EM, Zöchling N, Neubert U, Meurer M and Volkenandt M: No evidence for Borrelia burgdorferi-specific DNA in lesions of localized scleroderma. J Invest Dermatol 104 23-26, 1995.

11. Weide B, Walz $\mathrm{T}$ and Garbe C: Is morphoea caused by Borrelia burgdorferi? A review. Br J Dermatol 142: 636-644, 2000.

12. Aberer E, Neumann R and Stanek G: Is localised scleroderma a Borrelia infection? Lancet 2: 278, 1985.

13. Cunningham BB, Landells ID, Langman C, Sailer DE and Paller AS: Topical calcipotriene for morphea/linear scleroderma. J Am Acad Dermatol 39: 211-215, 1998.
14. Kreuter A, Gambichler T, Breuckmann F, Rotterdam S, Freitag M, Stuecker M, Hoffmann K and Altmeyer P: Pulsed high-dose corticosteroids combined with low-dose methotrexate in severe localized scleroderma. Arch Dermatol 141: 847-852, 2005.

15. Vilela FA, Carneiro S and Ramos-e-Silva M: Treatment of morphea or localized scleroderma: Review of the literature. J Drugs Dermatol 9: 1213-1219, 2010.

16. Constantin MM, Cristea CM, Taranu T, Bucur S, Constantin T, Dinu A, Jinga M and Nita IE: Biosimilars in dermatology: The wind of change. Exp Ther Med 18: 911-915, 2019.

17. Raducan A, Bucur S, Caruntu C, Constantin T, Nita IE, Manolache $\mathrm{N}$ and Constantin MM: Therapeutic management with biological anti-TNF- $\alpha$ agent in severe psoriasis associated with chronic hepatitis B: A case report. Exp Ther Med 18: 895-899, 2019.

18. Diab M, Coloe JR, Magro C and Bechtel MA: Treatment of recalcitrant generalized morphea with infliximab. Arch Dermatol 146: 601-604, 2010.

19. Dumitrascu MC, Stanescu AMA, Bejan C, Sandru F, Toader DO, Radavoi GD, Cotirlet A, Judea PCT and Diaconu CC: Obesity and its implications on stress urinary incontinence. Rev Chim (Bucharest) 70: 3660-3662, 2019.

20. Mertens JS, Seyger MM, Kievit W, Hoppenreijs EP, Jansen TL, van de Kerkhof PC, Radstake TR and de Jong EM: Disease recurrence in localized scleroderma: A retrospective analysis of 344 patients with paediatric- or adult-onset disease. $\mathrm{Br} J$ Dermatol 172: 722-728, 2015. 